\title{
Concentrations of glycerophosphocholine, phosphocholine and free inorganic phosphate in the luminal fluid of the rat testis and epididymis
}

\author{
B. T. Hinton and B. P. Setchell \\ A.R.C. Institute of Animal Physiology, Babraham, Cambridge CB2 4AT, U.K.
}

\begin{abstract}
Summary. Measurements were made on micropuncture samples of luminal fluids. The concentration of GPC was highest in the caput and corpus regions of the epididymis, that of phosphocholine changed little along the length of the rat epididymis and there was approximately a 3-fold increase of concentration of inorganic phosphate in the luminal fluid from caput epididymidis to ductus deferens. The estimated total phosphate appeared to equal that of the sum of the phosphate derived from the above compounds. The concentrations of these compounds in the luminal fluid of the testis and in blood plasma were very low.
\end{abstract}

\section{Introduction}

The concentrations of glycerophosphocholine (GPC) in the tissue of the mammalian epididymis (Dawson \& Rowlands, 1959; Scott, Wales Wallace \& White, 1963) are much higher than those found in the testis (Scott et al., 1963). However, no estimations of GPC and related compounds in the epididymal luminal fluid have been made except for fluid from the cauda epididymidis and ductus deferens (Dawson, Mann \& White, 1957; Dawson \& Rowlands, 1959; Brooks, Hamilton \& Mallek, 1974). Since the spermatozoa mature in the epididymal luminal fluid and it has been suggested that phospholipids are involved in this process (Evans \& Setchell, $1979 \mathrm{a}, \mathrm{b}$ ), it seemed relevant to measure the concentrations of GPC in the luminal fluid from various points along the rat epididymis; the same samples were analysed for phosphocholine and inorganic phosphate which have not been previously studied. It is hoped that this study may provide information on the composition of the specialized microenvironment that is provided by the epididymis for the maturing spermatozoa.

\section{Materials and Methods}

\section{Animals}

Adult male Porton-Wistar rats weighing 350-450 g were obtained from the Institute colony and were anaesthetized by i.p. injection of urethane (1.2 mg ethyl carbamate/g body wt; Fisons, Loughborough, U.K.). One testis and epididymis were exposed through a scrotal incision and prepared for micro-puncture as previously described (Hinton, Dott \& Setchell, 1979a; Hinton, Snoswell \& Setchell, 1979b). Rete testis fluid was collected from the rats by the method of Tuck, Setchell, Waites \& Young (1970) as modified by Setchell \& Main (1975).

\section{Microanalysis}

Estimation of GPC and phosphocholine involved perchloric oxidation followed by measurement of the released inorganic phosphate. In preliminary experiments using thin-layer chromato- 
graphy, inorganic phosphate, phosphocholine and GPC were found in the luminal fluid of the rat epididymis and had to be separated before oxidation of GPC and phosphocholine. A cellulose thin layer plate (pre-coated plastic sheet; Polygram Cel 300; Camlab, Cambridge, U.K.) was placed in a chromatography tank containing the solvent (ethanol:880 ammonia : water-saturated phenol : water, $6: 3: 2: 1$, by vol.: Marley, Morris \& White, 1977). After washing for 10-12 h the plate was air-dried, thoroughly rinsed in diethyl ether and then dried again.

Samples $(100 \mathrm{nl})$ of sperm-free luminal fluid (Hinton, Setchell \& White, 1976) or known amounts of standards (GPC and phosphocholine, kindly provided by Dr R. M. C. Dawson) were applied to the washed plate approximately $3 \mathrm{~cm}$ from the end. The cellulose plate was run with the above solvent for 5-6 h, air-dried, washed in diethyl ether and dried again. The plate was sprayed with a molybdate reagent (Sheltawy \& Dawson, 1969), air-dried and the areas containing the phosphorus were identified from their blue appearance after exposure to ultraviolet light.

For measurement of the inorganic phosphate released after perchloric oxidation the method of Sheltawy \& Dawson (1969) was modified for the small sample volumes. The area around each blue spot on the plate was cut out, the cellulose scraped from the plate and transferred to small glass test-tubes ( $50 \mathrm{~mm}$ length; $6.5 \mathrm{~mm}$ o.d.) which had been thoroughly cleaned by adding perchloric acid (70\%) and heating to $220^{\circ} \mathrm{C}$ for $30 \mathrm{~min}$, rinsed with glass-distilled water and dried. Two similar-sized areas not coloured blue on the plate were scraped to act as blanks. Perchloric acid (70\%: Fisons, Analar grade), $40 \mu \mathrm{l}$, was added to each tube, the tubes were covered with glass caps, and the samples were allowed to digest very carefully at $220^{\circ} \mathrm{C}$ for 30 min in a heated metal block. The tubes were then cooled and the inorganic phosphate estimated. Samples of rat epididymal luminal fluid were also analysed without chromatographic separation (to measure the total phosphate) and without oxidation (to measure the free inorganic phosphate). For the latter, perchloric acid $(40 \mu \mathrm{l})$ was added but the tubes were not heated.

For the colorimetric measurement of inorganic phosphate, $240 \mu$ distilled water, $20 \mu \mathrm{l}$ ammonium molybdate (4\% in $9 \%$ perchloric acid: Hopkin \& Williams, Romford, U.K.) and $6 \mu$ l sodium 7-amino-1,3-naphthalenedisulphonate (ANSA: Eastman, Rochester, U.S.A.), purified by the method of Fiske \& Subbarow (1925), were added to each tube. The contents were thoroughly mixed between additions of each reagent. The tubes were then placed into a boiling water bath $\left(100^{\circ} \mathrm{C}\right)$ for $10 \mathrm{~min}$, allowed to cool and the optical density of the blue colour formed was read against a reagent blank in a microcuvette at $830 \mathrm{~nm}$ (Gilford Spectrophotometer). A series of standards (2-16 nmol inorganic phosphate) were analysed by the same procedure and all standards and samples were assayed in duplicate.

\section{Plasma}

Blood samples were collected from rats and the plasma separated by centrifuging at $1500 \mathrm{~g}$ for $15 \mathrm{~min}$. Protein was precipitated from the plasma using a chloroform : methanol mixture $(2: 1$ $\mathrm{v} / \mathrm{v})$ and the water-soluble fraction $(200 \mu \mathrm{l}$, after electrophoresis to remove the ions) was applied to a strip of Whatman No. 1 filter paper, approximately $3 \mathrm{~cm}$ from the end. The filter paper was placed into a chromatography tank containing the ethanol:ammonia:phenol: water solvent as used above and the chromatogram was run for approximately $24 \mathrm{~h}$. The phosphorus-containing compounds were detected and assayed as previously described.

\section{Results}

The results are given in Table 1. GPC occurred in slightly higher concentrations in luminal fluids from the caput and corpus regions than in those from the distal cauda or ductus deferens. The maximum concentration was approximately $50 \mathrm{~mm}$. Phosphocholine was present at about half 





this concentration and there was very little change in concentration in the luminal fluid along the epididymis except for a slight increase in the proximal cauda. The concentration of inorganic phosphate increased approximately 3 -fold along the epididymis and in the cauda reached values similar to those for phosphocholine.

The total phosphate in the micropuncture samples approximately equalled the sum of the phosphate derived from GPC, phosphocholine and inorganic phosphate. There was very little change in the concentration of total phosphate in the luminal fluid along the epididymis. GPC, phosphocholine and inorganic phosphate concentrations in blood plasma and in the luminal fluids of the testis were very low.

The observed concentrations of all the phosphorus-containing compounds were less than the values calculated from the concentration in the fluid from the proximal caput and the amount of fluid reabsorbed beyond that site (Table 1; see Hinton, White \& Setchell, 1980, for method of calculation).

\section{Discussion}

To achieve these estimates of the concentration of GPC in the luminal fluid at various points along the rat epididymis, it was necessary to scale down the analytical techniques by a factor of 50 as well as using micropuncture techniques to obtain the samples. Our values for the concentration in the cauda and ductus deferens agree with those from an earlier study by Brooks et al. (1974) who measured approximately $40 \mathrm{mM}-\mathrm{GPC}$ in a mixture of luminal fluid from the cauda epididymidis and ductus deferens. Our results also agree with the findings of Dawson \& Rowlands (1959) that the concentration of GPC is higher in the tissue of the rat caput and corpus region than in the cauda, and of Scott et al. (1963) that GPC secretion does not occur in the rabbit testis. The concentration of GPC estimated in the rat epididymal luminal fluid is not as high as that found in the cauda epididymal luminal fluid of the rabbit (60 mM: Jones \& Glover, 1973) and boar ( $80 \mathrm{~mm}$ : Hinton et al., 1979b).

Since our results agree with those of Dawson \& Rowlands (1959), who also reported that the head of the rat epididymis possessed greater GPC synthetic activity than did the tail, they do not support the implications of the findings of Bjerve \& Reitan (1978). These workers found that phospholipase A, which is responsible for the breakdown of lecithin to lysolecithin and free fatty acids, was 10 times higher in activity in the cauda than in the caput, implying that GPC should also be higher in the caudal region. However, Bjerve \& Reitan (1978) admit that the activity of the enzyme in vitro may not reflect its activity in vivo. The concentration of GPC in the epididymis would also depend on the rate of removal.

Previous workers estimated GPC without chromatographic separation or by measuring liberated choline after hydrolysis and therefore did not observe the significant amounts of phosphocholine and inorganic phosphate reported in the present paper. Bjerve \& Reitan (1978) suggested that phosphocholine may be produced by the conversion of GPC by a glycerophosphinicocholine cholinephosphohydrolase (EC 3.1.4.38). If this suggestion were correct, an increase in the concentration of phosphocholine in the luminal fluid along the rat epididymis would be expected. However, the present study shows that there was very little difference in the concentration of phosphocholine along the epididymis. Phosphocholine may therefore be absorbed, as the figures in Table 1 suggest, or be a secretory product of the caput epididymal epithelial cells, being formed by the activity of choline kinase, an enzyme known to be present in other tissues (Bjørnstadt \& Bremer, 1966; Sundler \& Akesson, 1975).

The appearance of free inorganic phosphate in the luminal fluid at concentrations which increase from caput to ductus deferens was unexpected since ram and bull rete testis fluid contain very low concentrations of inorganic phosphate (see Setchell, 1970). There are several possibilities for its origin in the epididymis: non-enzymic breakdown of GPC or phosphocholine 
during storage of the sample, breakdown of GPC or phosphocholine by a specific enzyme, or specific secretion of inorganic phosphate by the epididymal epithelium.

However, all samples were stored frozen $\left(-20^{\circ} \mathrm{C}\right)$ and assayed for inorganic phosphate within a few days of collection, and the measurements of inorganic phosphate were very similar from animal to animal, so the possibility of non-enzymic breakdown seems unlikely. Since Bjerve \& Reitan (1978) were not able to find free choline in whole tissue, specific secretion of inorganic phosphate into the luminal fluid in the caput epididymidis seems the most plausible interpretation.

Secretion may be confined to the caput because the increased inorganic phosphate concentrations along the length of the epididymis beyond this site can be accounted for by water reabsorption as shown in Table 1. GPC and phosphocholine also appear to be secreted only in the caput region of the epididymis. These data would also suggest that some inorganic phosphate, GPC and phosphocholine are lost along the epididymis, probably due to reabsorption or metabolism by the epididymis or by the maturing spermatozoa.

We thank Mr Neville Clarke for help in solving some of the analytical problems that were involved. The investigation was financially supported by the World Health Organization.

\section{References}

Bjerve, K.S. \& Reitan, L.J. (1978) The presence of an androgen controlled phospholipase $A$ in rat epididymis. Int. J. Androl., Suppl. 2, 574-591.

Bjørnstadt, P. \& Bremer, J. (1966) In vivo studies on pathways for the biosynthesis of lecithin in the rat. $J$. Lipid Res. 7, 38-45.

Brooks, D.E., Hamilton, D.W. \& Mallek, A.H. (1974) Carnitine and glycerylphosphorylcholine in the reproductive tract of the male rat. J. Reprod. Fert. 36, 141-160.

Dawson, R.M.C., Mann, T. \& White, I.G. (1957) Glycerylphosphorylcholine and phosphorylcholine in semen, and their relation to choline. Biochem. J. 65, 627-634.

Dawson, R.M.C. \& Rowlands, I.W. (1959) Glyceryl phosphorylcholine in the male reproductive organs of rats and guinea-pigs. Quart. J. exp. Physiol. 44, 2634.

Evans, R.W. \& Setchell, B.P. (1979a) Lipid changes during epididymal maturation in ram spermatozoa collected at different times of the year. J. Reprod. Fert. 57, 197-203.

Evans, R.W. \& Setchell, B.P. (1979b) Lipid changes in boar spermatozoa during epididymal maturation with some observations in the flow and composition of boar rete testis fluid. J. Reprod. Fert. 57, 189-196.

Fiske, C.H. \& Subbarow, Y. (1925) The colourimetric determination of phosphorus. J. biol. Chem. 66, 375400.

Hinton, B.T., Setchell, B.P. \& White, R.W. (1976) The determination of myo-inositol in micropuncture samples from the testis and epididymis of the rat. $J$. Physiol., Lond. 265, 14-15P.

Hinton, B.T., Dott, H.M. \& Setchell, B.P. (1979a) Measurement of the motility of rat spermatozoa collected by micropuncture from the testis and from different regions along the epididymis. J. Reprod. Fert. 55, 167-172.
Hinton, B.T., Snoswell, A.M. \& Setchell, B.P. (1979b) The concentration of carnitine in the'luminal fluid of the testis and epididymis of the rat and some other mammals. J. Reprod. Fert. 56, 105-111.

Hinton, B.T., White, R.W. \& Setchell, B.P. (1980) Concentrations of myo-inositol in the luminal fluid of the mammalian testis and epididymis. J. Reprod. Fert. 58, 395-399.

Jones, R. \& Glover, T.D. (1973) The collection and composition of epididymal plasma from the cauda epididymidis of the rabbit. J. Reprod. Fert. 34, 395403.

Marley, P.B., Morris, S.R. \& White, I.G. (1977) Concentration of prostaglandins $E$ and $F$, fructose and glycerylphosphorylcholine in ram semen obtained by electro-ejaculation or artificial vagina and in vesicular fluid. Theriogenology 8, 33-43.

Scott, T.W., Wales, R.G., Wallace, J.C. \& White, I.G. (1963) Composition of ram epididymal and testicular fluid and the biosynthesis of glycerylphosphorylcholine by the rabbit epididymis. J. Reprod. Fert. 6, 49-59.

Setchell, B.P. (1970) Testicular blood supply, lymphatic drainage, and secretion of fluid. In The Testis, Vol. 1, pp. 101-239. Eds A. D. Johnson, W. R. Gomes \& N. L. VanDenmark. Academic Press, New York.

Setchell, B.P. \& Main, S.J. (1975) The blood-testis barrier and steroids. In Hormonal Regulation of Spermatogenesis, pp. 223-233. Eds F. S. French, V. Hansson, E. M. Ritzen \& S. N. Nayfeh. Plenum Press, New York.

Sheltawy, A. \& Dawson, R.M.C. (1969) Separation and estimation of phospholipids. In Chromatographic and Electrophoretic Techniques, Vol. 1: Chromatography, pp. 450-493. Ed. I. Smith. Heinemann, London. 
Sundler, R. A Akesson, B. (1975) Biosynthesis of phosphatidylethanolamines and phosphatidylcholines from ethanolamine and choline in rat liver. Biochem. J. 146, 309-315.
Tuck, R.R., Setchell, B.P., Waites, G.M.H. \& Young, J.A. (1970) The composition of fluid collected by micropuncture and catheterization from the seminiferous tubules and rete testis of rats. Pflügers Arch. ges. Physiol. 318, 225-243.

Received 12 June 1979 